\title{
FRUIÇÃO EM ARTES E O PROCESSO DE MEDIAÇÃO NAS ATIVIDADES EDUCATIVAS NO CRCP: UM RELATO DE EXPERIÊNCIA
}

\section{FRUITION IN ARTS AND THE MEDIATION PROCESS IN EDUCATIONAL ACTIVITIES AT CRCP: AN EXPERIENCE REPORT}

DOI: http://dx.doi.org/10.5965/1984317815022019238

Igor Vieira e Sá Tolentino

Universidade do Estado de Minas Gerais tolentas@gmal.com

\author{
Aline Nunes Carneiro \\ Universidade do Estado de Minas Gerais \\ aline.nunes@uemg.br
}

\section{RESUMO:}

Pretendo com este trabalho estudar a mediação em uma exposição, com o objetivo de analisar o processo de mediação e a fruição de arte na ação educativa, ocorridas no Centro de Referência da Cultura Popular e Tradicional Lagoa do Nado, junto a alunos da Educação Infantil. A partir de uma pesquisa bibliográfica, realizei um levantamento de informações sobre o Processo de Mediação e Fruição em Arte, levando à análise do relato de experiência apresentado no artigo. Percebi ao longo das minhas experiências como mediador cultural, que os grupos de visitantes geralmente desconheciam alguns movimentos, patrimônios e ramificações da cultura popular de Belo Horizonte. Além disso, quando iniciei o estágio extracurricular no CRCP, não recebíamos visitações das turmas de Educação Infantil, apesar de haver uma demanda por parte das escolas. Como resultado, foi possível explorar conceitos de autores que abordam noções do ensino de arte e mediação, de adequação de linguagem em relação ao público alvo, nas atividades de apreciação da arte visual e música.

Palavras-chave: Fruição em arte. Processo de Medição. Educação Infantil.

\begin{abstract}
With this work I intend to study the mediation in an exhibition, with the objective of analyzing the art mediation and the appreciation of Arts in the educational action, which took place at the Reference Center of Popular and Traditional Culture Lagoa do Nado, with students of Early Childhood Education. From a bibliographic research, I conducted a survey of information about the Art Mediation and Appreciation in the Arts, leading to the analysis of the experience report presented in the article. I realized throughout my experiences as a cultural mediator that visitor groups were often unaware of some movements, heritage and ramifications of Belo Horizonte popular culture. In addition, when I started the extracurricular internship at CRCP, we did not receive visits from preschool classes, although there was a demand from schools. As a result, it was possible to explore authors' concepts that address notions of art teaching and mediation, language adequacy in relation to the target audience, in the appreciation of visual art and music. Keywords: Appreciation in the Arts. Art Mediation. Early Childhood Education.
\end{abstract}




\section{INTRODUÇÃO}

Durante minhas experiências no Centro de Referência da Cultura Popular e Tradicional Lagoa do Nado (CRCP), tive a oportunidade de entrar em contato com a educação não formal. Este estágio extracurricular me fez refletir sobre a docência nesses espaços, levando em consideração o trabalho dos mediadores culturais. Nesse sentido, o objeto de estudo deste artigo foram as mediações que realizei ao longo do período de estágio, entre junho de 2015 e junho de 2017.

Como mediador cultural, pude observar e interagir com vários tipos de públicos. A maior parte do público frequentador desse espaço era constituída, em grande maioria, por alunos e professores da rede pública da educação. Ao longo das minhas vivências, notei que esses grupos de visitantes geralmente desconheciam alguns movimentos, patrimônios e ramificações da cultura popular de Belo Horizonte. Além disso, quando iniciei o estágio extracurricular no CRCP não recebíamos visitações das turmas de Educação Infantil, apesar de haver uma demanda por parte das escolas. Dessa forma, ajudei a construir uma adaptação das mediações para as crianças das UMEIS (Unidade Municipal de Educação Infantil), e também para as Creches conveniadas, permitindo uma inclusão dessa faixa etária. Para facilitar o acesso desse público, a equipe do CRCP desenvolveu uma parceria com a Secretaria de Educação (SMED), que possibilitou a visitação desses grupos no espaço cultural.

Depois da construção e implementação dessas mediações, surgiram as seguintes questões: Como as crianças dos anos iniciais da educação fruem em artes? Quais são os elementos que compõem a mediação cultural? O objetivo geral deste trabalho foi investigar o Processo de Mediação e a Fruição em Artes, na ação educativa ocorridas no CRCP. Para isso, levantei uma série de fundamentações teóricas relacionadas com o assunto. O estudo das estratégias de mediação envolvem inúmeros fatores, desde o objetivo da instituição, a relação da exposição com o público, até a formação da equipe e de materiais adequados. 
Para dar suporte às discussões, elaborei uma pesquisa bibliográfica que, segundo Gil (1991), é uma investigação sobre materiais já publicados, constituídos principalmente de livros, artigos e periódicos. Ao longo da pesquisa aqui realizada, me deparei com o conceito de mediação. As ideias da autora Ana Mae Barbosa em "Arte/ Educação Como Mediação Cultural e Social” (2009), define o Processo de Mediação e identifica o mediador e as partes mediadas (público ou visitantes). Juntamente, Marta Kohl de Oliveira determina o que são ferramentas e signos dentro de uma mediação no documentário "Coleção Grandes Educadores Lev Vygotsky". Para relacionar as temáticas dos processos de mediação e o ensino de artes, utilizarei a Referência Curricular Nacional para a Educação Infantil (RCN), do Ministério da Educação (1998). Esse material contempla os aspectos da Fruição em Artes da Educação Infantil no ambiente escolar. Além disso, utilizo das falas e textos de Robert Ott (1997) sobre arte como conhecimento, e de Paulo Freire (1989) em seu livro "A importância do ato de ler: em três artigos que se completam", sobre leitura do mundo. Com essa base teórica foi possível realizar uma análise em torno das mediações que pratiquei ao longo do estágio, explicitando tanto como ocorreram a fruição das artes, como também, os domínios das mediações.

O texto que segue está dividido em três seções, tratando de aspectos essenciais na análise do Processo de Mediação e Fruição em Artes: a $1^{a}$ seção, Fruição em Artes, fala sobre a concepção de artes como linguagem, arte como conhecimento e leitura de mundo. A $2^{a}$ seção, Processo de Mediação, discorre sobre o que é mediação, mediador e público (as pessoas mediadas), signos e ferramentas. A $3^{a}$ seção, por sua vez, fala sobre o Relato de Experiência e as análises desenvolvidas a partir do mesmo.

Com a pesquisa, verifiquei como acontecia o Processo de Mediação na exposição do CRCP, identificando quem era o destinatário, o mediador, o que é levado em consideração para haver a mediação, os signos e os instrumentos de mediação. Também comento como aconteceu a Fruição em Artes, e qual linguagem foi utilizada para trabalhar com o público infantil, utilizando a arte visual e a música. 


\section{FRUIÇÃO EM ARTES}

Segundo BRASIL (1998), várias pesquisas foram desenvolvidas no início do século, em muitos campos das ciências humanas. Nesse processo, foram trazidos dados importantes sobre o desenvolvimento da criança, sobre seu processo criador e sobre as artes das inúmeras culturas. Surgiram autores como Herbert Read e Viktor V. Lowenfeld, que formularam princípios inovadores, valorizando a livre expressão e a sensibilização para o experimento artístico como orientações. Essas orientações trouxeram contribuições para que se valorizasse a produção criadora infantil, mas o princípio revolucionário que defendia a necessidade e a capacidade da expressão artística para todos, aos poucos, se transformou em um "deixar fazer" sem nenhum tipo de intervenção, no qual a aprendizagem das crianças pôde evoluir muito pouco.

Nos anos 60, Richard Hamilton, Richard Smith, Joe Tilson e Eduardo Paolozzi, na Newcastle University, lançavam as bases teórico-práticas do DBAE, isto é, Arte-Educação Baseada em Disciplinas, trabalho desenvolvido pelo Getty Center of Education in the Arts, influenciados pelo Basic Design Movement e pelas Escuelas al Aire Libre, 1916, no México. Buscava-se, com o desenvolvimento do fazer artístico, a leitura do nacional e de sua História, a solidificação da consciência da cidadania do povo (SILVA, 1999, p. 50).

"Deixar fazer" ou "laissez-faire" foi, segundo Silva (1999), oriundo do abstracionismo e do expressionismo. Essa prática fortalecia "a abordagem de que a arte se baseava apenas no sentimento, deixando-a marginalizada dentro dos currículos escolares" (SILVA, 1999, p. 2). Em vários países a ideia de que a aprendizagem artística era uma consequência automática dos processos de desenvolvimento, ocasionaram um movimento pela mudança nos rumos do ensino da arte. Surge a comprovação de que o desenvolvimento artístico é resultado de formas complexas de aprendizagem e, dessa maneira, não ocorre automaticamente à medida que a criança cresce.

Foi, entretanto, o movimento de crítica literária e ensino da literatura americana reader response que, em diálogo com nossa especificidade terceiro-mundista, inspirou a designação de "leitura de obra de arte" para 
um dos componentes da triangulação ensino-aprendizagem. O movimento reader response não despreza os elementos formais, mas não os prioriza como os estruturalistas o fizeram; valoriza o objeto, mas não o cultua, como os de construtivistas; exalta a cognição, mas na mesma medida considera a importância do emocional na compreensão da obra de arte. O leitor e o objeto constroem a resposta à obra numa piagetiana interpretação do ato cognitivo e, mais ainda, vigotsquiana interpretação de compreensão do mundo. Assimilação e acomodação na relação leitorobjeto cons-troem a resposta estética (BARBOSA, 1995, p. 62)

Essas formas complexas de aprendizagem são influências culturais, seja por meio de materiais e suportes com que faz seus trabalhos, seja pelas imagens e atos de produção artística que observa na TV, na internet, em gibis, rótulos, estampas, obras de arte, trabalhos artísticos de outras crianças, etc.

As crianças têm suas próprias interpretações, ideias e impressões sobre a produção de arte e o fazer artístico. Essas construções são elaboradas a partir de suas experiências ao longo da vida, que envolvem a relação com o mundo dos objetos, o contato com a Arte, a produção de trabalhos e os tensionamentos no seu próprio fazer. As crianças observam, sentem, agem, refletem e elaboram sentidos das suas experiências. A partir disso, constroem significações sobre como se fazem, o que significam, e para que servem a arte e as produções culturais.

Nessa lógica, segundo BRASIL (1998), as artes visuais devem ser concebidas como uma linguagem que tem estruturas e características próprias. A aprendizagem, no âmbito prático e reflexivo, se dá por meio da articulação dos seguintes aspectos:

- Fazer artístico - centrado na exploração, expressão e comunicação de produção de trabalhos de arte por meio de práticas artísticas, propiciando o desenvolvimento de um percurso de criação pessoal;

- Apreciação - percepção do sentido que o objeto propõe, articulando-o tanto aos elementos da linguagem visual quanto aos materiais e suportes utilizados, visando desenvolver, por meio da observação e da fruição, a capacidade de construção de sentido, reconhecimento, análise e identificação de obras de arte e de seus produtores; De acordo com BRASIL (1998), "fruição refere-se à reflexão, conhecimento, emoção, 
sensação e ao prazer advindo da ação que a criança realiza ao se apropriar dos sentidos e emoções gerados no contato com as produções artísticas" (BRASIL, 1998, p. 89).

- Reflexão - considerado tanto no fazer artístico como na apreciação, é um pensar sobre todos os conteúdos do objeto artístico que se manifesta em sala, compartilhando perguntas e afirmações que a criança realiza instigada pelo professor e no contato com suas próprias produções e as dos artistas.

Dessa forma, o desenvolvimento da capacidade artística e criativa deve estar apoiado, segundo BRASIL (1998), no contato com a produção de arte presente nos museus, igrejas, livros, reproduções, internet, ateliês de artistas e artesãos regionais, feiras de objetos, espaços urbanos etc. Deve estar também na prática reflexiva das crianças ao aprender, que articula a ação, a percepção, a sensibilidade, a cognição e a imaginação.

No caso desse relato de experiência, foi muito importante refletir que a arte possibilitou o conhecimento. $O$ ensino de arte em museus constitui um componente essencial para a arte/educação, segundo os estudos de Ott (1989), "A arte pode assumir diversos significados em suas tantas dimensões, mas como conhecimento proporciona meios para a compreensão do pensamento e das expressões de uma cultura" (OTT, 1989, p.113).

As obras de arte transmitem concepções estéticas, mas os museus também refletem as condições culturais da sociedade. Essa consideração convida para uma participação mais ativa dos indivíduos em relação à arte. Partindo dessas ideias, Ott (1989) registra que o ensino da crítica nos museus possibilita uma educação que auxilia os alunos no desenvolvimento, aprendizagem, percepção e compreensão da arte como expressão das mais profundas crenças e dos mais caros valores da civilização. Nesta perspectiva de ensino crítico da arte Ott (1989) diz:

A arte, [...], reflete os valores estéticos intrínsecos da obra de arte e as preferências cognitivas dos alunos que estão nesse processo de aprendizagem, mas artes nos museus também reflete as condições 
culturais da sociedade.

[...] Aprender a entender as ideias e as aspirações de uma civilização e o reconhecimento das ideias artísticas como das maiores contribuições para a sociedade requer uma ativa, e não passiva, atuação em relação à arte. Essa participação ativa está entre as possibilidades de orientação dos alunos durante o ensino de crítica nos museus. (OTT, 1989, p. 114)

Dessa maneira, é possível perceber que o ensino da crítica dos museus auxilia a fruição dentro de exposições. É importante ressaltar que a participação ativa deve levar em consideração as diferentes leituras de mundo. Paulo Freire (1986) apresenta suas ideias a respeito do ato de ler, afirmando que "a leitura do mundo sempre precede a leitura da palavra" (FREIRE, 1986, p. 13). Para o autor, antes de construir a escrita, os homens e mulheres construíram a fala e antes da fala, eles liam o mundo ao seu redor. Freire (1986) narra esse processo a respeito de sua leiturização sobre o mundo:

[...] ia 'tomando distância' dos diferentes momentos em que o ato de ler se veio dando na minha experiência existencial. Primeiro, a 'leitura' do mundo do pequeno mundo em que me movia; depois, a leitura da palavra que nem sempre, ao longo de minha escolarização, foi a leitura da 'palavra mundo'. [...] Os 'textos', as 'palavras', as 'letras' daquele contexto - em cuja percepção me experimentava e, quando mais o fazia, mais aumentava a capacidade de perceber - se encarnavam numa série de coisas, de objetos, de sinais, cuja compreensão eu ia aprendendo no meu trato com eles nas minhas relações com meus irmãos mais velhos e com meus pais. (FREIRE, 1986, p. 13)

Dessa forma, ler as imagens do mundo sempre foi importante para entender a leitura da palavra escrita. Do ponto de vista do autor, as palavras se juntam nas imagens dos objetos e dos sinais. Ler a imagem significa remeter-se às ideias de Paulo Freire (1986) a respeito de que a leitura de mundo antecede a leitura das palavras. $O$ mundo da vida possui um saber diferente do mundo das palavras e dos livros.

O diálogo entre os dois autores contribui para a argumentação: fruir em artes depende do conhecimento do sujeito e de como ele faz a leitura do mundo. O conhecimento em arte vem da junção da experimentação, do entendimento e da informação. Não há como fruir em artes sem reconhecê-la como conhecimento. Nesse 
contexto, Barbosa (1991) explica que "o conhecimento em artes acontece na interseção da experimentação, da decodificação e da informação" (BARBOSA, 1991, p. 32).

A fruição das artes é observada tanto no campo das artes visuais, como também na música. Ela é um importante meio de expressão e de comunicação humana, relevando-se como fator determinante para a construção de singularidades que dão formas e sentidos às práticas culturais dos mais variados contextos (QUEIROZ, 2005). Tanto nas artes visuais como na música, a elaboração das vivências humanas produzem significados socioculturais e históricos, como menciona Queiroz:

A música como fenômeno cultural constitui uma das mais ricas e significativas expressões do homem, sendo produto das vivências, das crenças, dos valores e dos significados que permeiam sua vida. [...] A forte e determinante relação com a cultura estabelece para a música, dentro de cada contexto que ela ocupa um importante espaço com características simbólicas, usos e funções que a particularizam de acordo com as especificidades do universo sociocultural que a rodeia. (QUEIROZ, 2005, p. 52).

Sendo assim, com base nesses autores, entende-se que a fruição acontece reconhecendo a arte como conhecimento. Dessa forma, é possível interpretar, interrelacionar, compreender os pensamentos e as expressões de uma cultura.

\section{PROCESSO DE MEDIAÇÃO}

Antes de definir o Processo de Mediação, há a necessidade de definir o conceito de mediação. Segundo Barbosa (2009) "a mediação é um processo de acompanhamento semiótico e de inter-relação semiótica necessário que intervém em cada ocasião de fabricação de signos" (BARBOSA, 2009, p. 36). A ideia de mediação está relacionada com intermediar, ou seja, estar entre duas ou mais "coisas". Nessa relação processual de mediação, a autora apresenta o mediador (dispositivo, máquina ou humano), como um intérprete, organizador, estimulador, questionador, aglutinador do processo interpretativo. 


\section{EDUCAÇÃO, \\ ARTE'S E INCLUSÃO}

Pode-se então considerar que mediação é um domínio de ações que se dão no âmbito de:

- O objeto mediado;

- $\mathrm{A}(\mathrm{s})$ pessoa(s) e suas representações, crenças e conhecimentos envolvida(s) nesse processo de acesso à aprendizagem e/ou sensibilização intelectual de um dado fenômeno;

- $\mathrm{A}(\mathrm{s})$ pessoa(s) e suas representações, crenças e conhecimentos que tem um dado grau de expertises do dado fenômeno;

- O contexto cultural, social e/ou artístico de referência.

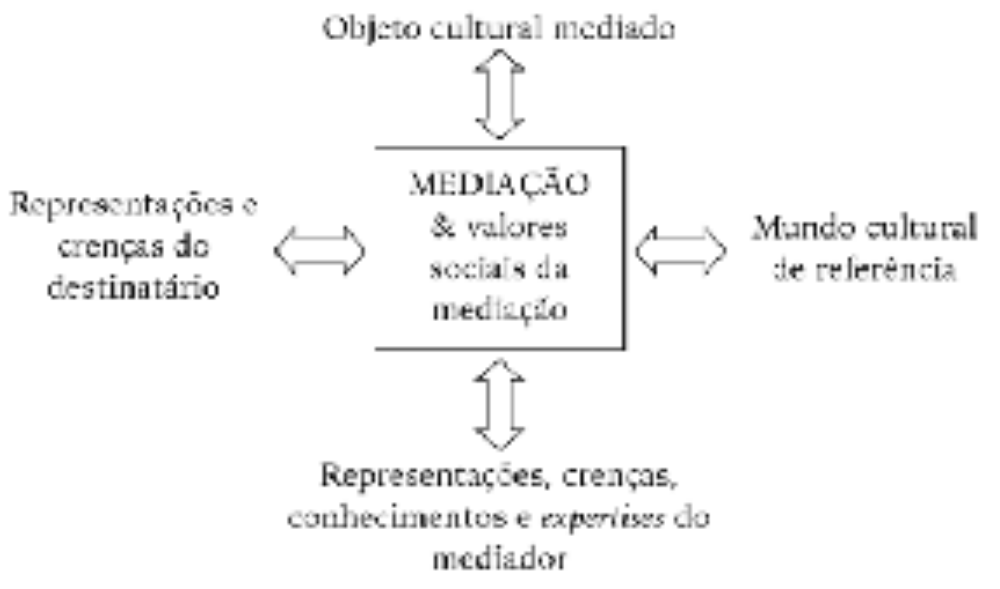

Figura 1 Mediação Cultural. Fonte: BARBOSA, 2006, p. 37

Nesse ponto percebe-se que essas competências se tocam simultaneamente e de maneira variável, segundo os meios e as concepções de cultura, a origem e a posição social do indivíduo em relação a sua legitimidade social e cultural.

Ainda segundo Barbosa (2009), as mediações são processos de acompanhamento semiótico que ordenam os caminhos procedimentais de difusão e de propagação de objetos culturais. "No quadro de mediações da cultura, elas se diferenciam consideravelmente em razão das concepções de cultura que revelam" (BARBOSA, 2009, p. 37). Na prática, percebe-se que mediação é o ramo da 
atividade de acompanhamento cultural e, mais raramente, uma ocasião de reflexão crítica sobre as diversas modalidades de construção dos fenômenos culturais.

No domínio cultural e artístico podem-se distinguir duas grandes abordagens da mediação. De acordo com Barbosa (2009), a primeira é a diretiva, que de forma mais simples, fornece só um sistema interpretativo, impondo um único tipo de compreensão do objeto cultural. Em sua forma mais requintada, produz sistemas interpretativos que tentam se articular ou não, e trabalhar conjuntamente. A segunda abordagem da mediação é construtivista, na qual, por meios de interrogações, problematizações, práticas, interações, se contribui para o surgimento da construção de um ou vários processos interpretativos pelo "destinatário" da mediação.

Diretivas ou construtivistas, as tarefas diretas da mediação mostram, sobretudo, os projetos de difusão das experiências e dos conhecimentos da arte e da cultura. Indiretamente, a mediação diretiva ou construtivista tem uma missão de democratização. As ajudas à interpretação servem, de maneira mais ampla, para entreter, restabelecer ou provocar vínculos entre o mundo da cultura e da arte e o referencial de um público adquirido ou potencial.

Conforme Barbosa (2009), as concepções da cultura centrípetas (voltadas para o campo da cultura cultivada e legitimada) e centrífugas (abertas a outros campos, como econômicos e sociais, entre outras) podem dar lugar a diferentes tipos de mediação, que são reagrupadas em três tendências: Imersão (Processo de Mediação se faz de maneira não formal no meio cultural); Diretivo (mediação é um dispositivo formal de transmissão de conhecimentos "eruditos", portanto que descendem "daqueles que sabem" para "aqueles que não sabem"); Construtivistas (mediações são negociações que implicam interativamente os parceiros de troca). Os principais modos de relação cultura-mediação figuram nas interseções entre as concepções da cultura e da mediação. Essas classificações têm finalidade de comparar e criticar uma mediação, conforme afirma Barbosa:

Esse mapa conceitual permite assinalar, classificar e nomear os diferentes modos de mediação. Suas operações possibilitam comparar 
e criticar os casos observados na prática. Particularmente, podemos situar os diversos casos observados sobre a diagonal que vai dos sistemas de reprodução cultural fechados aos sistemas abertos e interativos fundamentados nas discussões e no debate (BARBOSA, 2009, p. 39).

A mediação segundo Oliveira (2006), pode ser realizada entre instrumentos e signos. Entende-se que os instrumentos se relacionam com as "coisas" do mundo, usando ferramentas e instrumentos intermediários. Os signos são formas posteriores de mediação com natureza semiótica (OLIVEIRA, 2006). Os signos também aparecem em um plano totalmente simbólico, internalizados dentro do sistema psicológico de representação mental.

Barbosa (2009) afirma que o conceito de educação como mediação foi sendo construído ao longo dos séculos. Diversos autores atribuíam à natureza, ao sujeito ou ao grupo social o encargo da aprendizagem, colocando o professor como organizador, questionador, estimulador, aglutinador. Segundo a autora, o professor-mediador também possui essas características. Por outro lado, Paulo Freire (1998) emprega na atualidade a linha de que aprendemos uns com os outros mediatizados pelo mundo, tendo em vista que ninguém aprende sozinho e ninguém ensina nada a ninguém.

Levando em consideração a fala de Freire, o conceito de mediação como ensino passa a dar lugar a ideias. Assim, ao professor é atribuído o papel de mediar as relações dos aprendizes com o mundo que devem conquistar pela cognição. Segundo Barbosa (2009), a arte tem enorme importância na mediação entre os seres humanos e o mundo, apontando um papel de destaque para a arte/educação: ser a mediação entre a arte e o público.

O lugar experimental dessa mediação é o museu. Pensamos nos museus como laboratórios de arte. [...] Uma pesquisa, que ainda está para ser analisada, demonstra que o Processo de Mediação mais eficiente se dá nos lugares de arte, isto é, em museus e exposições. Crianças de sete ou oito anos quando desenham dentro dos museus, depois de verem uma exposição, (linha de base abaixo e céu acima) mais frequentemente do que quando desenham na escola de volta dessa visita. (BARBOSA, 2009, p. 13,14) 


\section{RELATO DE EXPERIÊNCIA}

Meu estágio extracurricular, base deste relato de experiência, foi realizado na região norte de Belo Horizonte, entre os bairros Planalto e Itapuã. O $\mathrm{CRCP}$, também conhecido como Parque Fazenda Lagoa do Nado, possui uma área de aproximadamente 311 mil metros quadrados e foi implantado em 1994. A sua infraestrutura é composta por biblioteca, sala multimeios, teatro de bolso ${ }^{1}$, teatro de arena, quadras poliesportivas, campo de futebol, pista para caminhadas e viveiro de mudas. O CRCP realiza diversas atividades de educação ambiental, cultura e esporte, juntamente com Fundação Municipal de Cultura (FMC) e da Secretaria Municipal de Esportes.

Com o intuito de preservar esta história e disseminar as práticas da cultura popular de Minas Gerais, a FMC criou o CRCP, que oferece ao público oficinas, espetáculos e exposições relacionadas às manifestações da cultura popular e tradicional da cidade. Também se estrutura como um espaço de discussão permanente sobre a cultura popular na capital, configurando-se como um centro de excelência e importante espaço de formação.

No CRCP, havia uma exposição chamada "Tradição e resistência: sujeitos, práticas e memórias da cultura popular em Belo Horizonte", que exibia um panorama da diversidade cultural contida na cidade. Foi considerada a especificidade de diferentes manifestações, como o teatro e a música, a partir de um acervo com vestimentas, fotografias, livros e outros objetos.

Durante a análise do relato de experiência no $\mathrm{CRCP}$, foram necessárias revisões de conteúdos teóricos acerca dos processos de mediação para identificar quem e quais são as características do(s) mediador(es) e do púbico (partes mediadas). Para um melhor esclarecimento, iniciarei este relato descrevendo as minhas funções como estagiário. Dentre elas, me responsabilizava pela realização do atendimento ao público, pelo monitoramento das visitas, pelo desenvolvimento das ações educativas e lúdicas

\footnotetext{
1 Teatro de bolso é um espaço dedicado às apresentações artísticas e culturais do CRCP.
} 
com crianças e jovens. Além disso, colaborava nas atividades administrativas do setor educativo. Por fim, ministrava uma capacitação para os professores da rede de ensino, sobre as atividades e metodologias utilizadas no CRCP.

A necessidade de criar a mediação para as crianças veio pelo acordo realizado com a SMED, para atender o público das UMEIS e Creches conveniadas da prefeitura de Belo Horizonte. A pedagoga e arte educadora Lecy Almeida coordenou a minha capacitação, bem como dos estagiários João Pedro Comini e Camila Mafalda. Juntos, construímos a mediação e todos os objetos utilizados para realização da ação educativa. Essa mediação foi organizada em cinco partes, sendo elas: Recepção; Apresentação da turma; Conhecendo o espaço e conceituando a cultura popular; Explorando a exposição "Tradição e Resistência"; Conhecendo o "Jardim das Cabeças".

\section{Recepção}

A recepção era iniciada quando as turmas e professores chegavam ao Parque Fazenda Lagoa do Nado. Era combinado previamente no telefone com os professores que os grupos fossem encaminhados para a parte externa do casarão, onde os mediadores aguardavam para dar as primeiras instruções. No encontro, era pedido para que (a)os professore(a)s direcionassem as crianças para os banheiros, e depois, para que guardassem os pertences em mesas preparadas com essa finalidade.

Depois da organização dos alunos, a mediação era iniciada com a brincadeira do "bom dia", que consistia em despertar a atenção das crianças. Os mediadores realizavam alguns combinados, caso houvesse alguma dispersão de atenção da turma. O combinado era firmado através da seguinte melodia:

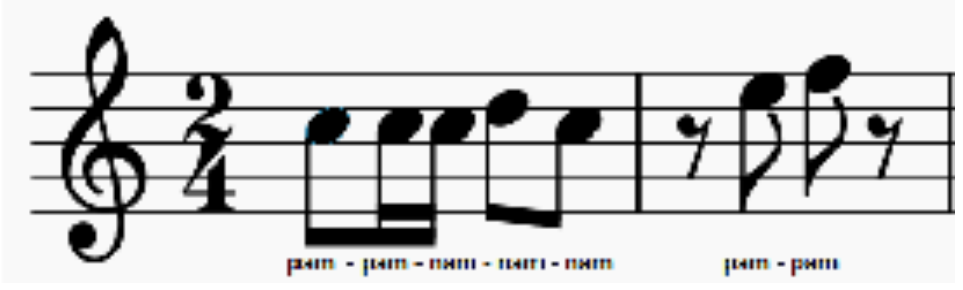

Figura 2 - Combinado Fonte: imagem produzida pelo autor. 
No primeiro compasso, o mediador cantava as primeiras notas e como resposta, as crianças cantavam o segundo compasso, como ilustrado na figura 2. Esse procedimento permitia captar a atenção das crianças sempre que elas pareciam se dispersar.

\section{APRESENTAÇÃO DA TURMA}

Após a brincadeira, encaminhávamos a turma para a biblioteca do CRCP. Formávamos uma roda, para nivelar o contato visual da turma com a do mediador. Isso facilitava a comunicação, e também sugeria um clima de brincadeiras de roda. Ao longo dessa organização, as crianças percebiam no centro da roda, que havia uma mala de viagem fechada. Em cima dessa mala, continham algumas notas de dinheiro de brinquedo, que eram objetos utilizados para a atividade seguinte.

Com os alunos em seus respectivos lugares, fazíamos uma dinâmica para perguntar seus nomes. Nessa atividade, as crianças apresentavam seus colegas, em vez de se apresentarem. Através da imitação, perguntávamos o nome da criança do seu lado, cochichando no seu ouvido, e depois falávamos o nome da criança em voz alta, para que a turma repetisse a mesma ação.

As atividades citadas acima foram utilizadas pois seguiam a linha lúdica aplicada nas UMEIS e creches conveniadas, das quais as crianças faziam parte. Pensando nelas como destinatárias da mediação, era necessário levar em consideração seus meios e concepções de cultura, origem e posição social, em relação às suas legitimidades sociais e culturais (BARBOSA, 2006). Ou seja, sendo seus contextos sociais lúdicos, as atividades também os deveriam ser.

\section{Conhecendo o espaço e conceituando a cultura popular}

Após a realização das apresentações, perguntávamos para as crianças o que havia de diferente dentro do círculo. A turma respondia que continha uma mala no meio da roda. Essa mala era um pretexto para contar a história da Lagoa do Nado. Nesse caso, identifiquei os objetos (a mala e o dinheiro), segundo Oliveira (2006), como 
instrumentos da mediação, pois eles são os motivadores dos alunos, para que fosse iniciada uma narrativa.

Essa atividade tinha o intuito de contar a história do CRCP, através de materiais construídos pela equipe do educativo. Ao montar uma fazenda de brinquedos, as crianças eram instigadas a explorar os materiais, de maneira a usar a imaginação e suas próprias vivências. Essa história permitia uma reflexão de como o espaço pode se transformar ao longo tempo.

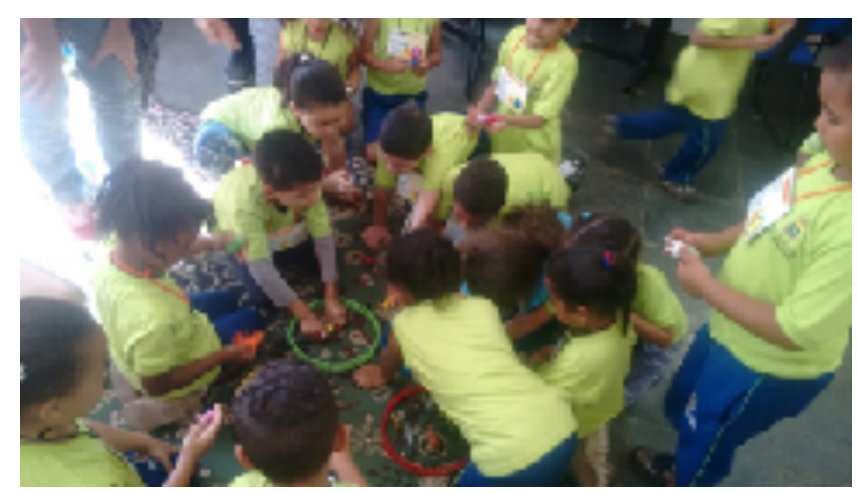

Figura 3 História CRCP. Umei Petrôpolis. Fonte:https://www.facebook.com/CentrodeReferenciaLagoadoNado

Nessa atividade, considerei o "fazer artístico" apresentado na matriz curricular das RCN (1998). Essa prática é centrada na exploração, expressão, comunicação e produção de uma atividade de arte, por meio de uma prática artística. Isso permite o desenvolvimento de um percurso de criação pessoal e coletiva.

Com a turma ainda em roda, dizíamos que seria realizada uma brincadeira da cultura popular. Perguntávamos se as crianças a conheciam, pois poderia ser do conhecimento delas. Caso elas não acertassem, respondíamos que se tratava da brincadeira batata quente. As regras originais ${ }^{2}$ do jogo foram alteradas para relacioná-lo com a exposição. Em primeiro lugar, a batata era uma pedra porque não gostaríamos que as crianças fizessem a associação de comidas com brincadeiras. Em segundo

\footnotetext{
2 Os jogadores formam um círculo, e um dos jogadores é vendado (ou fecha os olhos). Na roda, cada jogador deve passar algum objeto para quem está a sua direita, enquanto cantam e repetem "batata quente". No momento em que a pessoa vendada dizer "queimou", o jogador que estiver com o objeto em mãos, troca de lugar com a pessoa vendada.
} 
lugar, pela facilidade e para o exercício da imaginação. Quando a "batata" queimava os jogadores, perguntávamos para as crianças sobre aspectos da cultura popular, como: "quais comida vocês comem no almoço?", "quais brincadeiras vocês fazem na escola?", "quais festas nós temos durante o ano?", "quais músicas/danças acontecem nessas festas?". etc.". Dessa forma, iniciávamos a conceituação sobre a cultura popular.

Seguindo a linha de Barbosa (2009), o processo de acompanhamento semiótico acontece na fabricação do conceito "cultura popular". Nessa mediação, organizávamos as ideias e estimulávamos o processo interpretativo deste conceito com perguntas das culturas de Minas Gerais. Assim, buscávamos esses significados nos conhecimentos das crianças, definindo para elas que as festas, as memórias, os costumes e as tradições, fazem parte da cultura popular.

Retomando a Figura 1, é possível observar que o objeto mediado é o conceito "cultura popular". Para essa definição, considerávamos as representações/crenças/ conhecimentos dos envolvidos (as crianças), bem como os seus graus de expertise3. Dessa maneira, conseguíamos buscar nos conhecimentos dos envolvidos, o contexto cultural/social/artístico de referência.

Outra reflexão interessante sobre todas as atividades apresentadas até agora, foi que a ação educativa, segundo os meios apresentados, se enquadrou na abordagem da mediação construtivista. Isso porque, segundo Barbosa (2009), por meios interrogativos, problemáticos, práticos, interativos, a mediação contribui para o surgimento da construção de um ou vários processos interpretativos pelo "destinatário" da mediação.

Retomando a narrativa do relato, seguíamos com outra atividade, que sugeria uma ligação com a exposição. Iniciávamos o assunto sobre as festas populares, distribuindo várias fotos com imagens das Festas de Nossa do Rosário e das Folias de Reis. Além disso, pedíamos para que as crianças identificassem os conteúdos das

\footnotetext{
${ }^{3}$ Expertise é uma palavra de origem francesa que significa experiência, especialização, perícia.
} 
fotos. Geralmente, as crianças relacionavam as imagens com o carnaval, demonstrando a composição de seu repertório cultural. Nessa atividade, ajudávamos com a ampliação desse repertório, mostrando nas fotos a diversidade de festas que se encontra no estado de Minas Gerais. Partindo dessa atividade, a relação com a exposição era construída, pois seu acervo possuía os mesmos conteúdos.

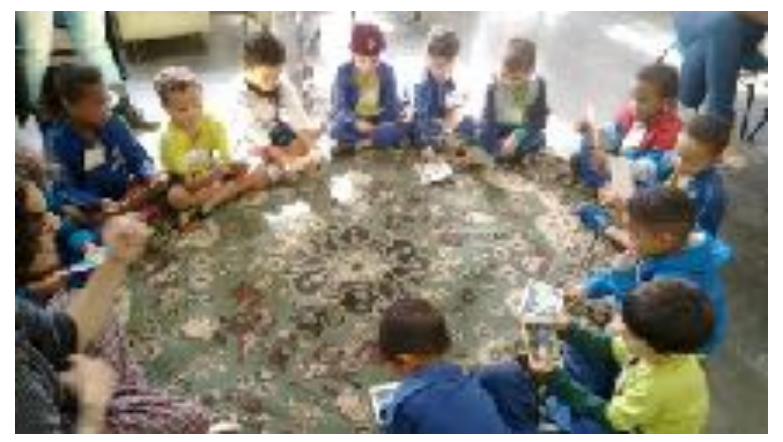

Figura 4 UMEI Santa Branca Fonte: https://www.facebook.com/CentrodeReferenciaLagoadoNado

Ao longo de todas as atividades propostas, destaquei os objetos utilizados durante a mediação. A mala, o dinheiro, os brinquedos da fazenda (cercas, animais, árvores) a pedra e as fotos, eram instrumentos intermediários, conforme a linha de Oliveira (2006), e portanto realizavam uma ação. Os objetos foram utilizados para despertar a curiosidade das crianças sobre os conteúdos abordados na mediação. Além disso, estes instrumentos intermediários proporcionaram a aproximação e contextualização do ambiente, possibilitando uma ligação com a história do CRCP e a exposição.

\section{EXPLORANDO A EXPOSIÇÃO TRADIÇÃO E RESISTÊNCIA}

Para a transição dos espaços, era proposto para as crianças cantarem alguma música do universo delas, como "borboletinha", "enquanto seu lobo não vem" ou "boi da cara preta". Lembro que essas músicas eram ensinadas pelos professores das creches, pois perguntávamos a eles quais canções eram utilizadas como ferramentas pedagógicas. Vale destacar que a maioria dessas músicas compõem o universo 
infantil, bem como representam canções da cultura popular. Além de facilitar a transição entre a biblioteca e o casarão, tomávamos essa ação de cantar as músicas como um reforçador entre as canções e a cultura popular.

Na porta da exposição, brincávamos de estátua ${ }^{4}$ com a turma para reunir sua atenção. O primeiro ambiente da exposição era a sala do casarão. Organizávamos as crianças, sentadas de frente para lareira. Dentro dela, havia uma televisão que integrava parte da exposição. De frente para as crianças, perguntávamos: "Nós entramos no casarão daquele fazendeiro que construiu a Lagoa do Nado, mas vocês estão vendo algum móvel aqui dentro?". As crianças procuravam, mas não encontravam nenhum móvel. Explicávamos que a casa tinha deixado de ser utilizada como moradia e se tornara uma exposição sobre a cultura popular em Minas Gerais. Dessa forma, a própria exposição servia para uma reflexão entre o que o espaço representava antes, e o que ele presentava no momento da mediação.

Essa explicação era necessária para fazer a ligação entre as fotos distribuídas na biblioteca e a primeira obra da exposição. Pedíamos para as crianças prestarem atenção na televisão da lareira, pois seria reproduzido um documentário. Instigávamos a turma para adivinharem qual festa poderia aparecer na tela, pois as fotos continham o mesmo conteúdo.

$\mathrm{Na}$ televisão da lareira era mostrado um trecho do documentário da premiação Mestres da Cultura Popular5 de 2014. A homenageada foi a ganhadora e rainha conga Isabel Casimira das Dores Gasparino. O trecho revelava aos alunos a "Guarda 13 de Maio" descendo uma rua em cortejo, utilizando instrumentos musicais (tambores, gungas e patangomes). A rainha Isabel falava sobre o reinado da guarda de congado, e o vídeo era encerrado com ela cantando uma música sobre Nossa Senhora do Rosário.

\footnotetext{
${ }^{4} \mathrm{Na}$ brincadeira da estátua, um dos participantes é escolhido para ser o líder e coloca uma música. Enquanto a música toca os jogadores dançam livremente, porém quando o líder disser: "Estátua!", a música para e todos os participantes devem congelar e manter a mesma pose sem mexer. No contexto da mediação do CRCP, na transição para o casarão, apenas falávamos estátua.
}

${ }^{5}$ Acessado em 05, dez. 2019. Disponível em: https://www.uai.com.br/app/noticia/e-mais/2014/11/26/ noticia-e-mais, 161837/fundacao-municipal-premia-lendas-vivas-da-cultura-belo-horizontina.shtml 


\section{EDUCAÇÃO, \\ ARTES E INCLUSÃO}

A utilização dessa mídia visual permitia às crianças uma aproximação maior com os aspectos do congado.

Utilizávamos quatro materiais confeccionados pelo educativo do CRCP, para a explicação da festa do congado. O primeiro era uma boneca que representava a Rainha Isabel. Ela possuía cerca de $60 \mathrm{~cm}$, construída com biscuit, e vestida com uma manta de pano e uma coroa de missanga. Pedíamos para as crianças adivinharem quem era a boneca, pois a Rainha havia aparecido no trecho do vídeo. Com a nossa ajuda, a boneca era passada de mão em mão para cada aluno.

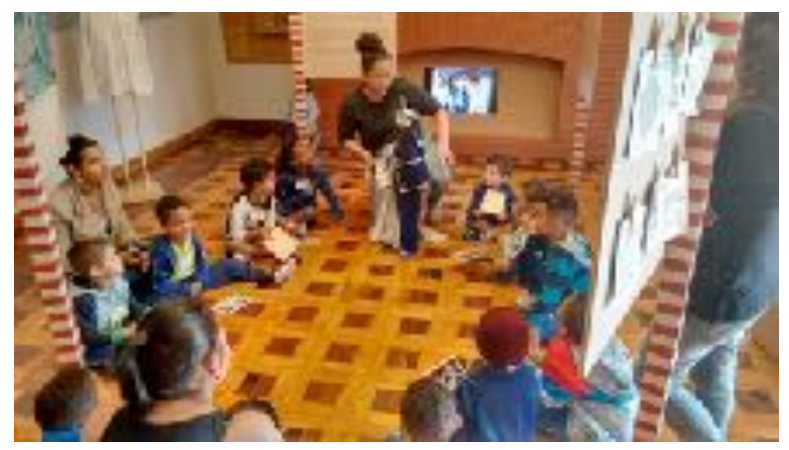

Figura 5 Boneca. UMEI Santa Branca. Fonte: https://www.facebook.com/CentrodeReferenciaLagoadoNado

O segundo material era o conjunto de cinco bonecos. Criados do mesmo material da rainha, eles representavam os congadeiros, e eram distribuídos para as crianças passarem entre a roda.

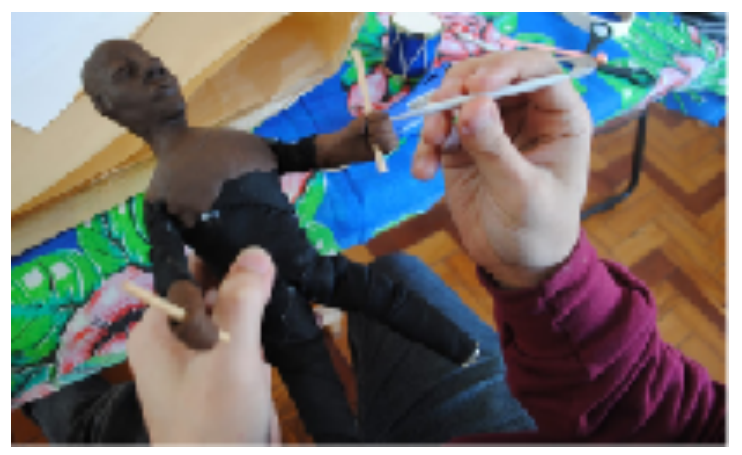

Figura 6 Congadeiro. Fonte: Imagem produzida pelo autor. 


\section{EDUCAÇÃO, \\ ARTES E INCLUSÃO}

O terceiro material era uma maquete composta por pequenos bonecos de plástico, vestidos de cetim. Cada boneco possuía seu instrumento musical e eram posicionados conforme se segue em uma guarda. Além dos congadeiros, havia o capitão, o rei, a rainha, o príncipe e princesa, em uma configuração que representava o cortejo da guarda de congado.

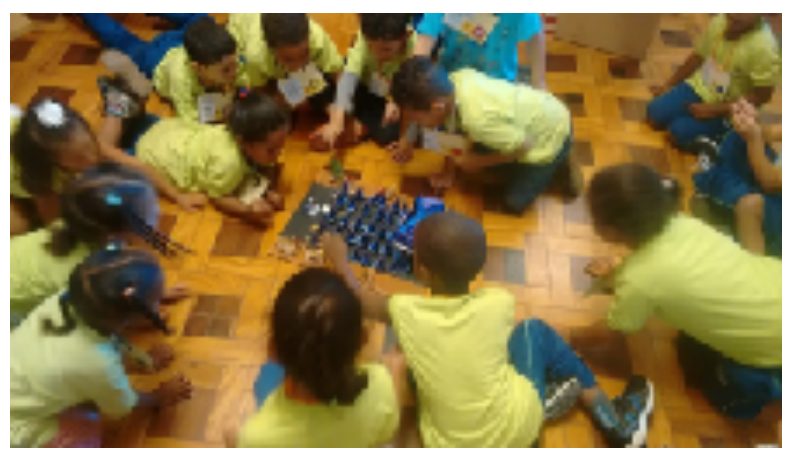

Figura 7 Maquete. Umei Petrópolis. Fonte:https://www.facebook.com/CentrodeReferenciaLagoadoNado

Por fim, o quarto material era composto por três instrumentos musicais percussivos do universo da guarda de congado (um tambor e dois patangomes). Com os instrumentos em mãos, realizávamos a seguinte atividade de repetição: Com cada instrumento, era batucado um conjunto de toques. Cada criança deveria repetir o mesmo conjunto de toques que havia escutado. Realizávamos a atividade com todas as crianças, e depois era permitido que tocassem os instrumentos livremente.

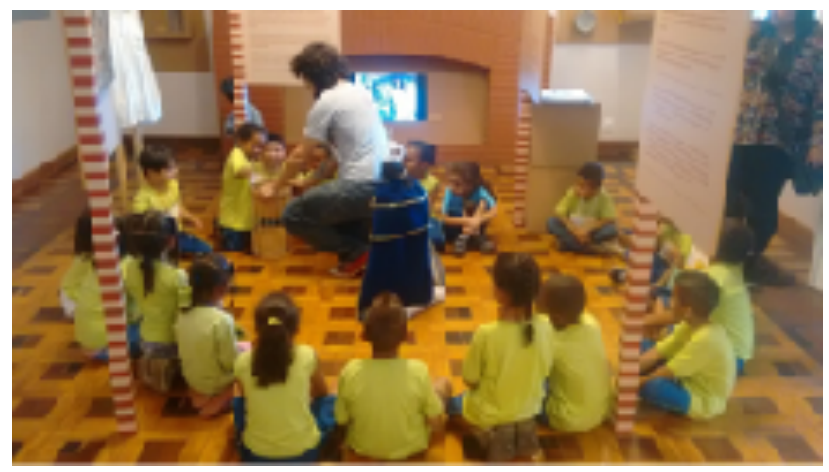

Figura 8 Tambor. UMEI Petrópolis. Fonte: https://www.facebook.com/CentrodeReferenciaLagoadoNado 
Depois de toda essa contextualização, os alunos eram instigados a perceberem as fotografias que compunham o acervo da exposição. Composta pela mesma temática, essas imagens eram representadas pelas maquetes e bonecos utilizados anteriormente.

Dessa forma, destaquei os instrumentos de mediação, com base nas ideias de Oliveira (2006) sobre os instrumentos e os signos da mediação. As crianças conhecem o congado através da mídia audiovisual, juntamente com bonecos e instrumentos musicais. Depois, elas reconhecem essas manifestações nas fotografias da exposição. Esse argumento vai de encontro com o texto de Ott (1989), no concerne "a percepção e compreensão da arte como expressão das mais profundas crenças e dos mais caros valores da civilização" (OTT, 1989, p. 114). Paralelamente, seguindo as ideias de Barbosa (2009), realmente acontecia uma mediação, pois segundo a autora, "mediação é o ramo da atividade de acompanhamento cultural e, mais raramente, uma ocasião de reflexão crítica sobre as várias modalidades de construção dos fenômenos culturais" (BARBOSA, 2009, p. 37).

As atividades do relato continuavam com o próximo homenageado do prêmio Mestres da Cultura Popular: José Luiz Lourenço, o Mestre Conga, compositor e sambista. Para apresentá-lo, utilizávamos um boneco parecido com a boneca da Isabel Casimiro. Brincávamos com as crianças, pedindo para elas cumprimentarem o boneco. Após uma breve contextualização da vida do Mestre Conga, perguntávamos para as crianças se tinham conhecimento de alguma música do gênero samba. Com uma resposta positiva, sugeríamos quem cantava a música. Caso a resposta fosse negativa, tocávamos com um pandeiro a música "samba lê lê" ao ritmo de samba. Ao cantarmos a música, entregávamos um pandeiro de brinquedo para realização da mesma atividade utilizada com os instrumentos do congado. 


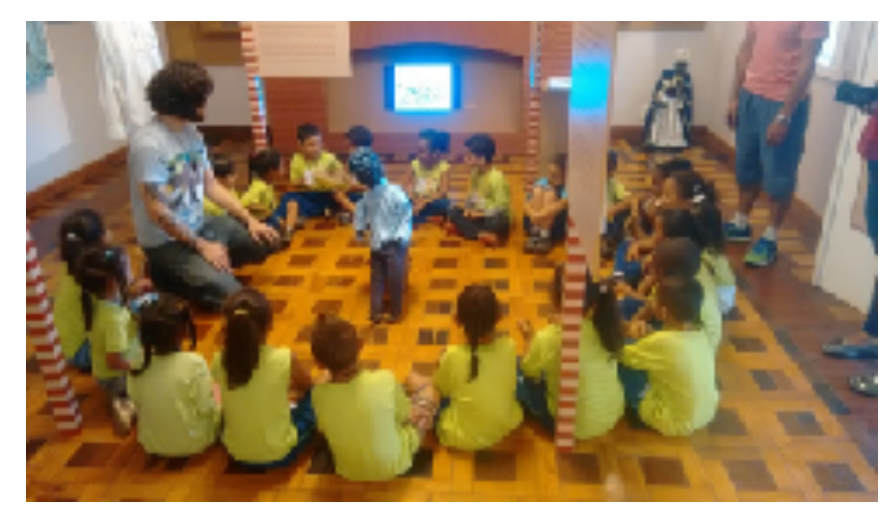

Figura 9 Mestre Conga. Umei Petrópolis. Fonte:https://www.facebook.com/CentrodeReferenciaLagoadoNado

Durante as mediações, recordo de um grande encantamento das crianças com as músicas e os instrumentos musicais. Em seu texto, Queiroz (2005) afirma que "a música é um fenômeno cultural que constitui uma das mais ricas e significativas expressões do homem, sendo produto das vivências, das crenças, dos valores e dos significados que permeiam sua vida" (QUEIROZ, 2005, p. 52). As músicas de roda, canções de ninar, entre outras, são utilizadas em salas de aula, pelas professoras das UMEls e Creches conveniadas. Desta forma, criava-se um vínculo afetivo entre as vivências das crianças, as novas atividades proporcionadas pelo educativo do CRCP e a exposição.

Segundo Cluver (1997), "modos de recepção ou leitura de textos verbais, visuais e musicais dependem muito da educação e formação de cada indivíduo; dependem de hábitos fomentados pelas comunidades interpretativas, bem como das condições e contextos de recepção de textos" (CLUVER, 1997, p. 33). Uma das manifestações da linguagem humana é a artística, por isso fica clara a inter-relação das artes dentro da exposição, já que no tempo da vivência da mediação acontecem ligações entre as imagens, as brincadeiras e as músicas.

Vale a pena fazer uma relação entre a forma de "ler" o mundo de Freire (1986) com a afirmação de Queiroz (2005) sobre a música, pois a música como linguagem representa o "produto das vivências, das crenças, dos valores e dos significados que permeiam sua vida" (QUEIROZ, 2005, p. 52). A leitura do mundo está intrinsecamente 


\section{EDUCAÇÃO, \\ ARTES E INCLUSÃO}

ligada à ideia da representação das músicas dentro do contexto social de cada indivíduo, porque existe essa dependência da educação e formação de cada um, assim como a construção dos signos. Identifiquei toda essa relação quando destaquei as atividades com os instrumentos musicais. Atribuíamos um significado histórico e cultural para os instrumentos a partir do momento em que eles eram apresentados pela guardas de congado ou pelos sambistas. Em síntese, as crianças tocavam esses instrumentos obtendo uma nova vivência cultural.

\section{CONHECENDO O “JARDIM DE CABEÇAS"}

De volta ao relato, encaminhávamos as crianças para a parte externa do casarão, onde elas seriam convidadas a conhecer a última parte da visita ao CRCP. Como iríamos deslocar de espaço novamente, pedíamos para as crianças cantarem as músicas citadas anteriormente nessa transição. Deslocávamos para outro local chamado "Figuras Urbanas", criado pelo artista plástico Norberto Santos de Souza, o Mestre Thibau. Essas obras se integravam à paisagem do Parque Fazenda Lagoa do Nado. As obras tratam-se de esculturas feitas em eucaliptos, compondo rostos e casebres, representando negros e as favelas do Brasil. Incentivávamos as crianças a perceberem de qual tipo de material as esculturas eram feitas com perguntas sobre as esculturas. 


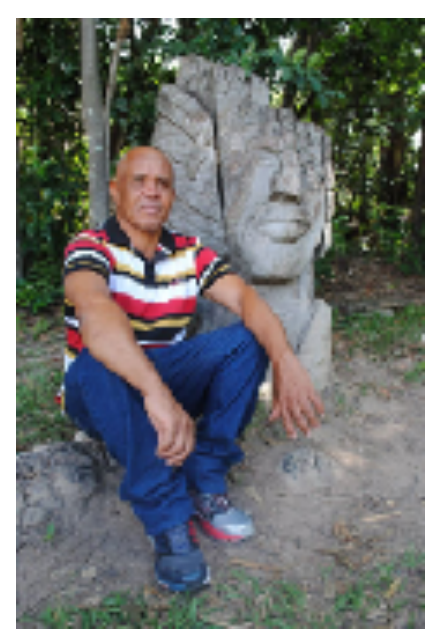

Figura 10 Mestre Tibhau e Figuras Urbanas. Fonte: https://www.facebook.com/CentrodeReferenciaLagoadoNado

Explicávamos e relacionávamos o contexto histórico e cultural das obras, estimulando uma leitura para cada escultura. Pedíamos para as crianças tocarem e observarem as esculturas, de maneira a comparar os traços das pessoas negras com as brancas. Além disso, perguntávamos se as composições das casas nas esculturas pareciam com a composição das casas nos seus bairros. Novamente, a ideia da leitura de mundo de Freire (1986) se faz presente ao longo da mediação. A visita era encerrada após a apresentação da última escultura, terminando assim, a mediação no CRCP. Depois disso, pedíamos para o(a)s professor(a)es responderem um questionário, citando os pontos positivos e negativos, além da opinião deles sobre a mediação.

\section{CONCLUSÃO}

Como afirmei anteriormente, o relato de experiência foi fundamental para a compressão sobre Fruição em Artes e mediação. Cumpre lembrar que a construção da mediação com o público infantil foi desenvolvida por uma Pedagoga/Arte Educadora, e três estagiários. Depois da formação inicial, todo o processo de construção da mediação foi realizado através de tentativa e erro, seguido pelo direcionamento de nossa mentora. Percebo que a linguagem utilizada correspondia à idade das crianças, 
pelo fato de entrar em acordo com as RCN. Utilizávamos da linguagem que compunha o universo infantil para que houvesse um melhor entendimento das crianças.

A partir do tópico "Fazer artístico" do mesmo documento, destaco neste relato que, tanto na construção da fazenda de brinquedos, como nas atividades dos instrumentos musicais, aconteciam atividades lúdicas e artísticas, possibilitando um livre brincar das crianças. Além de explorarem e se expressarem através desses objetos, percebi a comunicação envolvida durante essas brincadeiras. Não bastava entregar os brinquedos e os instrumentos para as crianças, o papel do mediador era fundamental na condução das brincadeiras, para que fizesse sentido ao contexto da exposição, e também para que não houvesse dispersão.

Sobre o tópico "Apreciação" das RCN, evidencio a construção dos sentidos de cultura popular. Observo que ao longo das atividades, o tempo todo foi trabalhado várias atividades artísticas e lúdicas, envolvendo os universos da Educação Infantil, da cultura popular de Minas Gerais e da exposição do CRCP. Tanto as ideias de Ott sobre o reconhecimento da arte como conhecimento, quanto a leitura de mundo de Paulo Freire, davam sentidos à mediação realizada.

A exposição se transformava a medida em que a interação das crianças se dava com os objetos construídos pelo educativo, o acervo e o próprio mediador. Essa afirmação vai de acordo com o tópico "Reflexão", porque esses conteúdos estavam intricadamente ligados. $\mathrm{O}$ contato com toda a produção do conhecimento das crianças era instigado o tempo todo pelo mediador.

$\mathrm{Na}$ mediação do CRCP, considerando os conceitos de instrumento e signo de Oliveira (2006), percebo como acontecia a fruição das obras na exposição. Encontravam-se no acervo, diversos objetos (fotografias, sistema audiovisual, esculturas e objetos do cotidiano de grupos populares), e, portanto os identifico como signos. Estes por sua vez, incorporavam diversos códigos, cuja leitura, no caso das crianças, era facilitada pela mediação. 
Explorávamos a linguagem visual para facilitar a comunicação com o público. As definições de cultura popular eram explicadas através de exemplos, mas a construção do conceito se tornava mais eficiente, ligando os objetos da exposição com as brincadeiras e instrumentos intermediários. Com isso, conseguíamos proporcionar uma vivência da cultura popular, parafraseando com a ideia de leitura de mundo de Freire (1986). Ou seja, a Fruição em Artes poderia acontecer a partir da relação dos conhecimentos construídos nessa vivência, com a identificação das manifestações no acervo da exposição.

Evidencio no relato três domínios de ações correspondentes à mediação: Objetos mediados, como os materiais construídos pela equipe do educativo e/ou as obras de arte; os Destinatários da mediação, como as crianças, bem como o(a)s professore(a)s participantes, pois ele(a)s agregavam e interagiam com as atividades; o Mundo cultural de referência como os conceitos de cultura popular, principalmente as culturas de Minas Gerais. Além disso, evidencio que através das brincadeiras, conseguíamos perceber o contexto social e cultural das crianças, a partir de suas atitudes e respostas.

Ao longo da minha experiência, percebi que muitas crianças não conheciam a manifestação do congado. Por meio das associações entre a manifestação com as outras festas populares, observei uma significativa assimilação da manifestação pelas crianças. Elas possuíam todo um repertório cultural que envolvia as brincadeiras populares, as festas e as músicas, sendo possível estipular algumas relações entre os objetos mediados. Levando em consideração os estudos de Barbosa (2009), percebo que a exposição do CRCP foi utilizada como laboratório de artes, pois foram realizadas várias experimentações conforme afirmado anteriormente. Antes do acordo realizado com a SMED, o educativo apenas realizava a mediação com os projetos da Escola Integrada, ou seja, com os alunos a partir dos oito anos de idade.

Percebo a necessidade de estender este artigo para projetos futuros, pois estas experiências levantaram muitas outras questões a serem investigadas acerca das mediações destinadas ao público da Educação Infantil. Além disso, esse é um assunto 
pouco abordado na literatura, pois a maior parte dos livros, artigos e documentos utilizados neste texto, fazem referências a crianças a partir dos sete anos. Outro aspecto importante do trabalho foi a inclusão das vivências musicais, que enriqueceram bastante a mediação, possibilitando uma aproximação entre a educação museal e educação musical.

\section{REFERÊNCIAS}

BARBOSA, Ana Mae. A importância da imagem no ensino da arte: Diferentes metodologias, in, A imagem no ensino da arte: Anos 80 e novos tempos, São Paulo Perspectiva, 1991.

Arte/Educação como mediação cultural e social/Ana Mae Barbosa e Rejane Galvão Coutinho (orgs.) - São Paulo: Editora UNESP, 2009.

Arte Educação Pós-Colonialista no Brasil: Aprendizagem Triangular. São Paulo: Comunicação e Educação, 1995.

BRASIL. Ministério da Educação e do Desporto. Secretaria de Educação Fundamental. Referencial curricular nacional para a Educação Infantil, Brasília, 1998.

CLUVER, Claus, Estudos interartes: conceitos, termos, objetivos. Trad. Claus Cluver e Sameul Titan Júnior. Literatura e Sociedade, São Paulo, n.2, 1997.

FREIRE, Paulo, 1921 - A importância do ato de ler: em três artigos que se completam / Paulo Freire. - São Paulo: Autores Associados: Cortez, 1989.

GIL, Antonio Carlos. Como elaborar projetos de pesquisa. São Paulo: Atlas, 1991.

MARINHO, Vanildo Mousinho, QUEIROZ, Luiz Ricardo Silva, Contexturas: o ensino das artes em diferentes espaços, Ed. Universitária, 2005.

OLIVEIRA, Marta Kohl. NPDGIRASSOL. Coleção Grandes Educadores Lev Vygotsky. Disponível em: <https://www.youtube.com/watch?v=T1sDZNSTuyE\&t=956s>. Acesso em: 09 de out. 2017.

OTT, Robert Willian, "Ensinando crítica nos museus". In: BARBOSA, Ana Mae (org.). Arteeducação: Leitura no subsolo. São Paulo: Cortez, 1997.

PARQUE MUNICIPAL FAZENDA LAGOA DO NADO. PORTALPBH. Disponível em: <http:// portalpbh.pbh.gov.br/pbh/ecp/comunidade.do? evento=portlet\&app=fundacaoparque\&pg=5521\&tax=21238>. Acesso em: 07 out. 2017.

SILVA, M. (1999). Ensino de arte nos Estados Unidos e no Brasil. Comunicação \& Educação, (14), 49-52. Disponível em: <https://doi.org/10.11606/issn.2316-9125.v0i14p49-52>. Acesso em: 02 dez. 2019. 
Recebido em 02 de outubro de 2018

Aprovado em 17 de março de 2020 


\section{ANEXOS}

\section{Dinâmica do "Bom dia" na recepção:}

A brincadeira do "bom dia" consistia em dar bom dia para os alunos, mas de uma forma diferente, conforme demonstro a seguir: "Bom dia turma (a turma responde). Nossa, que bom dia mais fraco, vamos fazer o seguinte, assim que eu levantar meu dedo, vocês me dão bom dia. Assim que eu abaixar, vocês vão fazer zip na boca (não respondem mais)". Eu levantava meu dedo algumas vezes para o desenvolvimento da brincadeira. Antes de iniciar outra atividade.

\section{Atividade da História da Lagoa do Nado}

"Essa mala era de um fazendeiro que chegou da Itália. Ele tinha usado todo o seu dinheiro para comprar uma fazenda, que hoje em dia, é onde estamos". Para tornar a história mais interativa, retirávamos da mala algumas cercas de brinquedo para construir a fazenda. Colocávamos uma vasilha grande com água, para representar uma lagoa. Tudo era distribuido no meio do circulo, perguntávamos para as crianças o que estava faltando na fazenda. As crianças eram instigadas a perceberem o que estava em torno da biblioteca, até sobre as árvores e os animais, mas apenas as árvores de brinquedos eram colocadas na atividade.

Os animais de brinquedo eram distribuídos para as crianças. São eles as vacas, cavalos, tartarugas, pássaros, galinhas da angola, borboletas, cachorros, macacos, patos, porcos e cabritos. Depois que as crianças recebiam os animais, havia um tempo para que eles brincassem com os brinquedos. Mais tarde instruíamos as crianças para colocarem para dormir os animais na fazenda para dar continuidade com a história. A ordem dos alunos na roda era fundamental para a organização da brincadeira.

Depois de deixarem os brinquedos, a história termina com o falecimento do 


\section{EDUCAÇ̃̃O, \\ ARTES E INCLUSÃO}

fazendeiro. Alguns animais da fazenda são "vendidos" e retirados do seus lugares, permanecendo apenas os animais que existem hoje na Lagoa do Nado. Depois de todos esses acontecimentos, algumas pessoas encontraram a fazenda e resolveram ocupa-la, para se divertirem. Porém esse espaço seria vendido, e as pessoas que compraram resolveram acabar com todas as árvores para a construção de um condomínio. Os personagens que estavam usando a fazenda se reunirão e fizeram um grande abraço gritando "Viva a Lagoa do Nado". Nesse momento pegávamos as mão das crianças e imitávamos o grito das pessoas que lutaram pela Lagoa do Nado. 